\title{
AUDITORIA NO SECTOR PÚBLICO: UM INSTRUMENTO PARA A MELHORIA DA GESTÃO PÚBLICA
}

\author{
Maria da Conceição da Costa Marques \\ Professora Adjunta do Instituto Superior de Contabilidade e Adm. de Coimbra - Portugal \\ E-mail: mcarvalheira@iscac.pt \\ José Joaquim Marques de Almeida \\ Professor Associado da Universidade Aberta - Portugal \\ Professor Coordenador do Instituto Superior de Contabilidade e Adm. de Coimbra - Portugal
}

\section{RESUMO}

O programa abrangente de reformas efectuado pelas administrações públicas, teve como resultado uma nova postura da Administração perante o cidadão, conhecida como Nova Gestão Pública (New Public Management). O papel dos Gestores Públicos é agora de maior responsabilidade, que devem gerir os recursos públicos de forma eficiente e eficaz. Este novo enquadramento requer por parte do Estado um controlo especializado, que possa aferir da correcta actuação dos responsáveis.

Os antigos procedimentos de fiscalização mostram-se insuficientes e novos mecanismos de controlo têm de ser instalados. A prática regular da auditoria no sector público, que atinja novos alcances, para avaliar da correcta aplicação dos recursos públicos, é cada vez mais uma realidade, embora exista ainda um longo caminho a percorrer. Conquanto se avance cada vez mais neste campo, o processo não se encontra generalizado, o que pode ser um desafio cada vez maior para os governos dos países.

As entidades públicas e as empresas privadas laboram segundo diferente objectivos, utilizam diferentes técnicas, o que em matéria de auditoria exige o desenvolvimento e adequação de métodos apropriados para as instituições públicas, para ir ao encontro das suas necessidades.

Face a este desiderato, este "paper" aborda a função auditoria e traça o respectivo enquadramento no contexto do sector público, referenciando o que em Portugal se faz nesta área.

Palavras-chave: Controlo, Auditoria, Gestão, Eficiência.

\section{ABSTRACT}

The broad reform program realized by public administrations resulted in the Administration's new attitude towards the citizen, which is known as New Public Management. Public Managers are now vested with greater responsibility and must manage public resources efficiently and effectively. This new framework requires a specialized control from the State, which is able to verify the responsible persons' correct performance.

The former supervision procedures reveal to be insufficient and new control mechanisms have to be installed. In order to evaluate the correct application of public resources, regular auditing practices in the public sector, which acquire a broader range, are increasingly occurring, although there is still a long way to go. While increasing advances are made in this area, the process is not generalized, which may be a bigger and bigger challenge for governments.

Public and private entities work according to different aims and use different techniques, which, in auditing terms, requires the development and adaptation of appropriate methods for public institutions, to attend to their needs.

In view of these facts, this paper deals with the auditing functions and outlines this framework in the context of the public sector, explaining what is done in Portugal in this sphere.

Keywords: Control, Auditing, Management, Efficiency.

Recebido em 06.07.03 • Aceito em 22.03.04 


\section{INTRODUÇÃO}

Nos últimos anos, na maioria dos países da OCDE, pôs-se em prática um programa abrangente de reformas direccionado a introduzir melhorias nos serviços prestados pelas administrações públicas, tentando ir ao encontro das suas necessidades e assegurar a eficiência e a qualidade desses serviços, sem descurar a aproximação aos cidadãos.

Essa nova postura da Administração junto dos cidadãos é conhecida como nova gestão pública (New Public Management) e procura avaliar a gestão num novo enquadramento, que se pauta pela introdução de modelos de gestão utilizados no sector privado.

Por outro lado, as recentes fraudes contabilísticas de grandes empresas norte-americanas, provocaram junto dos utilizadores (consumidores, investidores, stakeholders $^{1}$, etc.) a desconfiança na maioria dos organismos de controlo.

A ocorrência desses episódios, de graves consequências económicas, tornou-se um veículo privilegiado para que a auditoria venha a conquistar um espaço de merecida credibilidade. Neste contexto, também a auditoria pública vê aumentado o seu papel, na medida em que assegura o interesse colectivo.

Este trabalho enquadra e desenvolve as últimas tendências em matéria de auditoria pública e enfatiza o papel que a mesma pode desempenhar nas organizações estaduais.

\section{CONTROLO E SECTOR PÚBLICO}

\subsection{Controlo externo e controlo interno}

Num Estado de Direito, todas as actuais estruturas organizativas, quer do Estado e de todos os seus Órgãos, quer dos particulares, devem cumprir as normas jurídicas existentes nesse momento determinado.

Assim sendo, a administração e manejo dos bens e dos fundos públicos têm de se pautar pelo rigoroso cumprimento dos requisitos legais necessários, incumbindo aos organismos de controlo essa verificação. O alargamento e âmbito das competências destes órgãos tem por objectivo responder às exigências da sociedade moderna.

O Estado, como ente jurídico e social, evoluiu profundamente e a actividade financeira tomou nas organizações um lugar de relevo, que contribui de forma decisiva na formação das instituições.

O princípio da legalidade tem tido ao longo dos tempos um papel de primordial importância, estando hoje as organizações confrontadas com a necessidade de conjugar esta vertente tradicional com outros indicadores, indispensáveis ao processo decisório.

Torna-se, por isso, fundamental que se complete este regime legal com controles sobre a actuação dos gestores, para poder avaliar se a gestão económica dos recursos públicos (escassos) está a operar-se de forma correcta e se é alvo de controlo especializado. Ou seja, se está assegurada a gestão desses recursos de forma eficaz, eficiente, económica, equitativa e, hoje em dia, também ecológica. É precisamente aqui que a actuação dos órgãos de fiscalização e controlo se torna essencial.

Em Portugal, o sistema nacional de controlo das finanças públicas apresenta-se do seguinte modo:

Sistema Nacional de Controlo das Finanças Públicas

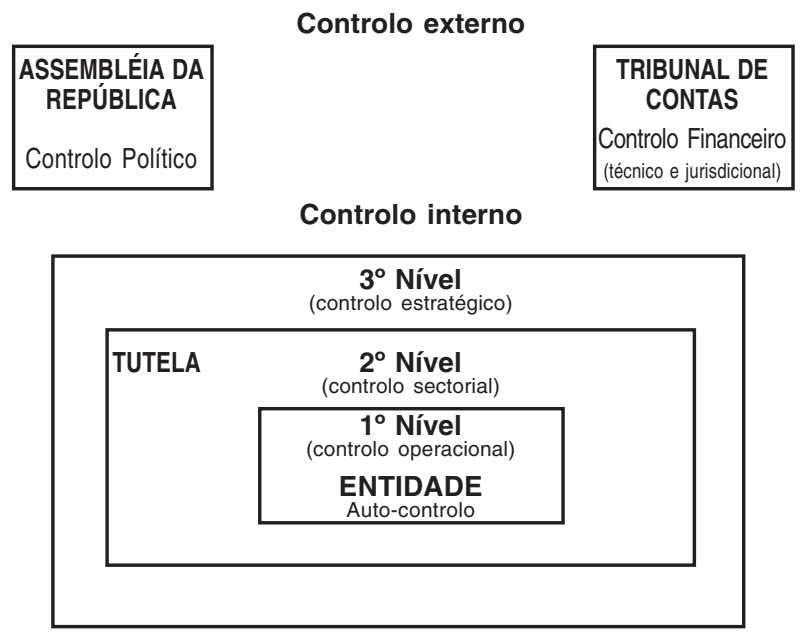

Fonte: Tribunal de Contas, 1999, p. 32

\section{Gráfico 1 - Administração Pública}

O controlo externo tem como principal característica a de ser efectuado por profissionais alheios à instituição, habilitados com qualificações técnicas e profissionais de elevado nível para exercer

${ }^{1}$ Partes interessadas nas demonstrações financeiras. 
a auditoria. Está fora de qualquer plano ou nível da gestão financeira do Sector Público, e pode e deve avaliar o controlo interno.

A utilização regular e racional dos fundos públicos constitui uma condição essencial da boa gestão das finanças públicas, e bem assim, dos objectivos alcançados. Desse modo, para que todo o processo atinja a eficácia desejada, torna-se indispensável que cada Estado disponha de uma entidade de fiscalização superior eficaz, conferindoIhe a lei total independência.

De acordo com a Constituição Portuguesa é o Tribunal de Contas $(\mathrm{TC})^{2}$ a entidade fundamental do sistema nacional de controlo financeiro externo - organismo independente - que tem poderes jurisdicionais sobre todas as entidades públicas, fiscaliza a legalidade e regularidade das receitas e das despesas públicas, aprecia a boa gestão financeira e tem autoridade para determinar responsabilidades financeiras.

A Lei $n^{\circ}$ 98/97, de 26 de Agosto - lei de organização e processo do Tribunal de Contas - consagra a este organismo a faculdade de exercer o controlo financeiro no âmbito da ordem jurídica portuguesa, tanto no território nacional, como no estrangeiro. Os poderes de jurisdição e de controlo financeiro do TC abrangem o Estado, as Regiões Autónomas, as Autarquias Locais, os institutos públicos e as instituições de segurança social.

Entidades de natureza pública ou privada, maioritariamente financiadas pelo Orçamento do Estado ou que nelas se verifique a existência de capitais públicos, estão também sujeitas aos poderes de controlo financeiro do TC.

O controlo interno é um plano de organização da empresa que incorpora um conjunto de métodos e procedimentos que assegurem a protecção dos activos e registos contabilísticos fiáveis, e que a actividade se desenvolva de forma eficiente e eficaz de acordo com objectivos da administração (MARQUES DE ALMEIDA, 1998d, p. 202).

Dependendo da dimensão da organização, também o controlo interno pode assumir maior ou menor relevância, sendo certo que em grandes organizações a implementação de um sistema de controlo interno é absolutamente imprescindível, para assegurar o cumprimento dos objectivos préestabelecidos.

Em Portugal, nos últimos anos, tem vindo a ser feito um esforço significativo em matéria de controlo interno, dado que até 1995 pouco ou nada se tinha idealizado sobre este assunto.

Assim, com o Decreto-Lei $n^{\circ} 166 / 98$, de 25 de Junho, o Governo instituiu o sistema de controlo interno da administração financeira do Estado (SCl), onde se realça a importância dada pelo Governo à função controlo, procurando promover a difusão de uma "cultura de controlo" em todos os níveis da administração financeira do Estado.

Com a institucionalização da Inspecção Geral da Administração Pública (IGAP), através do Decretolei $n^{\circ} 220 / 98$, de 17 de Julho, como inspecção de alto nível, com atribuições e competências de controlo estratégico, e com o pressuposto de que ao controlar a gestão de recursos humanos e a modernização administrativa, se está a controlar uma grande fatia do Orçamento do Estado, foi dado um passo significativo e de grande alcance.

A tão apregoada modernidade da Administração implica que se avaliem as instituições, e também os próprios agentes envolvidos, assegurando um modelo de responsabilização e de indicadores de performance de cada um dos intervenientes da Administração Pública. A IGAP pode dar um elevado contributo na consecução destes objectivos ao nível da responsabilização dos agentes e aferição dos resultados obtidos.

\subsection{Alcance e efeitos do controlo}

As entidades de controlo não podem apenas quedar-se pelo controlo do estrito cumprimento da legalidade por parte das administrações públicas, devem tender cada vez mais para o controlo da gestão, no qual se avalia o cumprimento de metas e objectivos. Quer isto dizer, que ao controlar-se a gestão de um determinado organismo público, deve avaliar-se a economia, a eficiência e a eficácia da sua actuação - a auditoria dos três "E", pois só assim se pode confirmar se foram cumpridos os programas e

\footnotetext{
${ }^{2}$ No artigo $216^{\circ}$ da Constituição da República Portuguesa, refere-se que "O Tribunal de Contas é o órgão supremo de fiscalização da legalidade das despesas públicas e de
} julgamento das contas que a lei mandar submeter-lhe....." 
alcançadas as metas e objectivos, em condições adequadas de tempo e de custo.

Essa vertente é de tal forma importante, que hoje em dia se torna usual serem os próprios cidadãos a querer saber se os recursos públicos foram utilizados e investidos de forma eficiente, tendo em conta a satisfação das necessidades colectivas. Segundo a AECA (2001, p. 36), com o controlo pretende-se obter uma apropriada e eficaz utilização dos fundos públicos, acentuando a procura de uma gestão rigorosa e regularidade na acção administrativa e a informação.

\subsection{Modalidades de controlo}

O controlo exercido pelo TC pode ser prévio, concomitante e sucessivo. O controlo prévio destina-se a verificar se os instrumentos geradores de despesa ou representativos de responsabilidades financeiras directas ou indirectas, se encontram em conformidade com a lei e têm cabimento orçamental.

O controlo a posteriori ou sucessivo, tem como objectivo a apreciação da execução orçamental do Orçamento do Estado (OE) e dos orçamentos das regiões autónomas, para emissão de pareceres sobre as contas, avaliar os sistemas de controlo interno, bem como proceder a auditorias de contas.

O controlo concomitante da actividade financeira pública, igualmente previsto na lei de organização e processo do TC (Lei $n^{\circ}$ 98/97), é aquele que é efectuado ao longo da gestão, aliás uma medida que vem sendo cada vez mais utilizada pelo Tribunal.

Em face das funções desempenhadas e dos mecanismos existentes, o que se espera é que a função fiscalizadora venha a resultar cada vez mais útil e especializada, contribuindo por tal via para a melhoria da gestão pública.

\section{A AUDITORIA DO SECTOR PÚBLICO}

\subsection{Enquadramento}

Para a IFAC ${ }^{3}$ a "Auditoria é uma verificação ou exame feito por um auditor dos documentos de prestação de contas com o objectivo de o habilitar a expressar uma opinião sobre os referidos documentos de modo a dar aos mesmos a maior credibilidade" (TC, 1999, p. 30).

A definição da INTOSAI ${ }^{4}$, segundo a mesma fonte, está mais voltada para as finanças públicas "Auditoria é o exame das operações, actividades e sistemas de determinada entidade, com vista a verificar se são executados ou funcionam em conformidade com determinados objectivos, orçamentos, regras e normas". Como se constata, existem aspectos comuns nas duas definições.

Sobre a auditoria no sector público, pode dizerse que está ainda a grande distância do que se faz no sector privado. Para as empresas torna-se por demais importante que as demonstrações financeiras transmitam uma imagem verdadeira e apropriada da situação financeira, dos resultados e também dos fluxos de caixa. Para as entidades públicas o que interessa, sobretudo, é que a gestão dos fundos públicos tenha sido adequada e que se pautou por critérios de legalidade; aliás, a vertente tradicional do controlo público.

Todavia, nos dias que correm, novas formas de gestão vão sendo adoptadas - a Nova Gestão Pública [New Public Management (NPM)] - pelo que a relevância e a transparência da informação são cruciais, assim como o controlo. O cidadão adquire um novo papel e torna-se elemento fundamental para a gestão pública, pois é a ele que a informação se dirige.

O modelo de prestação de contas tem vindo a ser alterado, precisamente porque são os cidadãos quem, através dos impostos, financia a actividade pública, daí que deva ter acesso à informação financeira pública. É aqui que o controlo externo ou auditoria externa assume grande relevo, pois a fiabilidade das contas pode não ser garantida se não for acompanhada de um relatório de auditoria. Não podemos deixar de referir o quão imprescindível se torna a realização de auditorias públicas e dos relatórios sobre as mesmas.

A auditoria operativa ou de economia, eficiência e eficácia, tem um papel de destaque nos novos contornos da NPM pelo facto de introduzir melhorias na eficiência e no controlo do output e na gestão por objectivos. 
Sem dúvida que a contabilidade pública é uma peça essencial do processo de reformas que vêm sendo feitas no sector público, mas existem dificuldade de pôr em prática, de forma imediata, as reformas entretanto operadas nesta área, dificuldades essas que têm diversas justificações, as quais resultam, em grande parte, de se procurar obter uma prestação de contas por objectivos.

Daí que se torne cada vez mais imperioso reforçar a prática regular da auditoria pública, e que essa atinja novos alcances que possam aferir da correcta aplicação dos fundos públicos, numa perspectiva de controlo de gestão da entidade, para no futuro poder caminhar-se para auditorias de avaliação da qualidade dos serviços prestados, como de resto sucedeu na Nova Zelândia, país pioneiro em matéria de auditoria pública. (TORRES: 2002).

Enquanto que nas empresas é a situação económico-financeira ${ }^{5} \mathrm{o}$ alvo de maior interesse, nas administrações públicas o que releva é a verificação da boa gestão financeira e dos recursos da entidade. Uma vez que ao Estado são atribuídas características específicas, distintas do sector empresarial, como seja a inexistência de um mercado competitivo, complexidade e lentidão na tomada de decisões, forte reacção à mudança e dificuldade em avaliar os outputs, é premente a realização de auditorias. Ain- da que cada vez mais se avance neste campo, o processo não se encontra generalizado, o que a nosso ver constitui um desafio cada vez maior aos governos dos países.

A auditoria é um dos meios que o Tribunal de Contas português utiliza para efectuar o controlo financeiro das entidades públicas sob sua jurisdição e, dadas as suas amplas competências e poderes de controlo, cada vez mais a auditoria, para além dos aspectos financeiros, visa também a aspectos de gestão, ambientais, de utilidade social, etc. (TC, 1999, p. 30).

\subsection{As Normas Internacionais de Auditoria do Sector Público}

Desde os finais do século XIX que os especialistas de contabilidade e auditoria, sobretudo dos países mais avançados, procuram regulamentar a sua profissão e harmonizar e homogeneizar as normas, práticas e relatórios. O sector público esteve presente praticamente desde o início, o que indicia o grau de importância que representa este sector para a profissão de auditoria.

O seguinte quadro dá-nos uma ideia dos organismos internacionais que emitem normas de auditoria:

\begin{tabular}{l|l|}
\multicolumn{1}{c|}{ ORGANISMO } & \multicolumn{1}{c|}{ COMPETÊNCIAS } \\
$\begin{array}{l}\text { INTOSAI- International Organization } \\
\text { of Supreme Audit Institutions }\end{array}$ & $\begin{array}{l}\text { Agrupa as entidades fiscalizadoras supe- } \\
\text { riores (órgãos de controlo externo dos } \\
\text { Estados membros) }\end{array}$ \\
\hline $\begin{array}{l}\text { International Federation of } \\
\text { Accountants (IFAC) }\end{array}$ & $\begin{array}{l}\text { Constituída em 1977, herdeira e } \\
\text { aglutinadora de diferentes organizações } \\
\text { internacionais de profissionais de conta- } \\
\text { bilidade e auditoria. }\end{array}$
\end{tabular}

International Federation of

Constituída em 1977, herdeira e bilidade e auditoria.

Agrupa as entidades fiscalizadoras superiores (órgãos de controlo externo dos

aud
Desenvolveu normas completas de audi- toria, que são uma referência para a pro- fissão em todo o mundo. aplicabilidade à auditoria do sector público

\section{IGAE - Intervención General de la Administración del Estado}

As normas ditadas pela IGAE aplicam-se a todas as auditorias que se realizem no âmbito do sector público estatal espanhol.
Numa fase posterior acrescenta-se a cada uma das normas comentários sobre a

As normas aprovadas em Outubro de 1991 constituem uma referência para a auditoria do sector público

As normas devem ser observadas pelos $\mathrm{OCEX}^{6}$, pelos auditores privados que desenvolvam trabalhos para o sector público.

Fonte: elaboração própria, baseado em AECA, p. 95/97

\section{Quadro 1}

\footnotetext{
${ }^{5}$ Numa perspectiva de obtenção de lucro.

${ }^{6}$ Órgãos de Controlo externo das comunidades autónomas.
} 


\subsection{Tipos de Auditoria do Sector Público}

Resultou da Declaração de LIMA sobre as linhas básicas da fiscalização, aprovadas no IX Congresso da INTOSAI, a necessária inter-relação entre o controlo e a economia financeira pública (AECA, 2001, p. 101), tornando-se num mecanismo regulador da legalidade, rentabilidade, utilidade e racionalidade das operações financeiras, a ponto de serem tomadas medidas correctivas. Em sequência, a auditoria é uma técnica ao serviço do controlo necessário, mas não deve considerar-se como um fim em si mesma.

Resulta, assim, que as técnicas e procedimentos de auditoria não podem ser os mesmos para todos os objectivos de controlo, devendo alguns deles adaptar-se aos fins pretendidos. Portanto, podem definirse diversos tipos de auditoria, em função dos objectivos visados:

Tipos de Auditoria

\begin{tabular}{|l|c|c|}
\hline Auditoria financeira & Auditoria de regularidade & Auditoria integrada \\
\hline Auditoria do cumprimento da legalidade & & \\
\hline Auditoria de Eficácia ou de Programas & Auditoria operativa & \\
\hline Auditoria de Economia e Eficiência & Auditoria de Sistemas e Procedimentos & \\
\hline
\end{tabular}

Fonte: AECA, 2001, p. 102

\section{Quadro 2}

Pina, V. y Torres, L. (2001) organizam o controlo e a auditoria no sector público da seguinte forma:

\section{CONTROLO E AUDITORIA NO SECTOR PÚBLICO}

\begin{tabular}{l|l}
$\begin{array}{l}\text { Em função da dependência do Órgão Auditor } \\
\text { Em função do seu objectivo }\end{array}$ & $\begin{array}{l}\text { Controlo internocontrolo externo } \\
\text { Controlo ou auditoria de legalidade }\end{array}$ \\
\hline Em função do seu alcance & $\begin{array}{l}\text { auditoria financeira ou contabilística } \\
\text { auditoria operativa ou de gestão } \\
\text { auditoria integrada }\end{array}$ \\
\hline Em função da sua periodicidade & $\begin{array}{l}\text { parcial ou limitada } \\
\text { auditoria completa }\end{array}$ \\
\hline Em função do momento & $\begin{array}{l}\text { continua } \\
\text { periodicidade anual } \\
\text { esporádica }\end{array}$ \\
\hline & $\begin{array}{l}\text { prévio ou a priori } \\
\text { simultâneo } \\
\text { a posteriori }\end{array}$ \\
\hline
\end{tabular}

Fonte: Pina, V. y Torres, L. (2001)

\section{Quadro 3}

A auditoria financeira tem como objectivo obter uma segurança razoável nas contas e verificar se as demonstrações financeiras sob análise expressam, em todos os seus aspectos significativos, a imagem fiel do património, da situação financeira e do resultado da gestão, em conformidade com os princípios contabilísticos geralmente aceites. Em Portugal é chamada de certificação legal de contas ${ }^{7}$.

No sector público, essas auditorias não apresentam diferenças significativas em face do sector privado. Exceptuando os "actores", as diferenças existentes são as que se relacionam com o controlo orçamental e contabilístico, com o conteúdo das peças contabilísticas e com os utentes da informação financeira.

No campo da harmonização internacional de princípios e normas contabilísticas e de auditoria, com a criação em Junho de 1986 do Public Sector Committee, comité permanente do Conselho da IFAC (International Federation of Accountants), está

${ }^{7}$ Efectuada em Portugal por Revisores Oficiais de Contas. 
a contribuir-se para a coordenação e harmonização das necessidades relativas à informação financeira, contabilidade e auditoria para todo o tipo de entidades públicas (PINA E PRADAS: 2001). Destaca-se o empenho na normalização e harmonização da auditoria pública efectuado pela International Organization of Supreme Audit Institutions - INTOSAI.

Auditoria do cumprimento da legalidade tem a ver com a importância dada ao cumprimento das normas legais no âmbito do sector público. O seu não cumprimento acarreta maiores conseqüências às organizações públicas, do que às privadas. Portanto, se entre os objectivos da auditoria se encontra a verificação dos aspectos legais, estamos perante uma modalidade de auditoria conhecida como do cumprimento.

Auditoria de regularidade constituem a maioria das auditorias que se efectuam no sector público, porquanto se inclui numa mesma auditoria, a auditoria financeira e a auditoria do cumprimento.

Auditoria de eficácia ou de programas tem como objectivo verificar em que medida foram alcançados os resultados e os objectivos pré-definidos para a entidade, nomeadamente programas, serviços, actividades e funções a auditar.

Auditoria de economia e eficiência tem a ver com a forma como a entidade gere os recursos humanos e materiais, ou seja, se tem em conta critérios de economia, o que significa adquirir ao mínimo custo e de forma eficiente, portanto, de modo produtivo.

Auditoria de sistemas e de procedimentos: esta modalidade de auditoria foi concebida mais para o sector público. Antes do seu aparecimento os seus objectivos ou não se enquadravam no âmbito da auditoria ou eram incluídos ou na auditoria de eficácia, ou na auditoria de economia e eficiência. Adequa-se a instituições que tenham de cumprir normas relacionadas com o Direito Administrativo e preocupa-se com a verificação do seu cumprimento, e ainda sobre a detecção de possíveis ineficiências.

Auditoria operativa resulta da conjugação das modalidades anteriores. A auditoria operativa ou auditoria da economia, eficiência e eficácia, assume um papel de relevância no contexto da nova gestão pública, uma vez que todas as atenções se viram para a melhoria da eficiência, no controlo do output e na gestão por objectivos.
Segundo Gauthier (citado por PRADAS: 2002) "em conjunto com o sistema contabilístico tradicional, que enfatiza o cumprimento da legalidade, foi emergindo um consenso sobre a necessidade de introduzir na informação fornecida pelas administrações públicas uma componente operativa que preste contas sobre o cumprimento dos objectivos numa perspectiva de eficácia e de eficiência". Norman, 1995 (citado por PRADAS: 2002) diz que a contabilidade pública é "um elemento essencial das reformas do sector público". Por outro lado, Pallot, citado pela mesma autora refere que "o quid pro quo do aumento da autonomia dos gestores está em incrementar a prestação de contas por resultados e em implementar mais práticas contabilísticas".

\subsection{Princípios e Normas de Auditoria no Sector Público}

Pina, V. y Torres, L. (2001) referem que as dificuldades em se estabelecerem normas técnicas de auditoria que garantissem a qualidade do trabalho, deram lugar à consideração de uns princípios e procedimentos básicos do trabalho de auditoria, de aceitação geral para toda a profissão, que viriam a ser designadas por normas de auditoria geralmente aceites.

Nesse campo, foi notável o empenho da INTOSAI que elaborou Normas de Fiscalização ou Auditoria de aplicação pelas Entidades Fiscalizadoras Superiores, de carácter orientativo. Note-se que tanto as normas de auditoria para o sector privado como as normas de auditoria do sector público se referem às características pessoais do auditor, à realização do trabalho e ao relatório de auditoria.

Sobre as características profissionais do auditor as normas destacam aspectos como a sua formação técnica, a sua independência e a sua adequada responsabilidade profissional. Em Espanha, os "Princípios e Normas de Auditoria do Sector Público" exigem do auditor as seguintes características: formação técnica e capacidade profissional; independência; diligência profissional; responsabilidade e segredo profissional. Em Portugal, o TC nos "Princípios aplicáveis aos auditores" inclui a independência, a competência e a diligência, em cujo âmbito se incluem as características exigidas pelas normas espanholas. 
O trabalho a desenvolver, de acordo com as normas, deve ter um planeamento adequado e respectiva supervisão, a análise do sistema de controlo interno da entidade e determinar o alcance dos procedimentos de auditoria a aplicar, com o objectivo de obter elementos destinados à elaboração de juízo válido e suficiente, como suporte das opiniões e conclusões.

Dessa forma, no documento a elaborar é fundamental seguir determinados princípios na realização do trabalho de auditoria, desenvolvidos de acordo com as respectivas normas:

\begin{tabular}{l|l}
\hline 1 & Planeamento \\
\hline 2 & Supervisão \\
\hline 3 & Controlo interno \\
\hline 4 & Evidência \\
\hline 5 & Revisão das normas legais \\
\hline 6 & Importância relativa e risco na auditoria \\
\hline
\end{tabular}

Quadro 4 - elaboração própria, baseado em

Pina, V. y Torres, L. (2001)

\section{OS RELATÓRIOS DE AUDITORIA EXTERNA DO SECTOR PÚBLICO}

\subsection{Características e especificidades}

A relevância dos relatórios de auditoria do sector público é diferente dos relatórios de auditoria do sector privado, o que se deve, em boa medida, aos seguintes factos:

- O leque de utilizadores da informação financeira do sector público é muito mais amplo;

- as administrações públicas devem prestar contas a todos os cidadãos.

A informação pretendida pelos utilizadores externos são diferentes, não obstante se reconhecer existirem pontos comuns, como seja o conhecimento da boa gestão dos recursos públicos e o que se espera que venham a fazer no presente e no futuro. De igual modo, também exigem que a informação financeira seja relevante e fiável, o que se obtém através de auditorias às demonstrações financeiras, realizadas por profissionais independentes e experientes.

Os cidadãos pretendem ter acesso à informação sobre a actuação dos responsáveis políticos que elegeram, para poder efectuar juízos e actuar em conformidade, caso venha a ser necessário.

Apenas com uma adequada divulgação da informação financeira pública, que possa estar disponível a todos os interessados, objecto de auditoria ou não, se consegue uma maior transparência da gestão do sector público. Esse objectivo assenta numa nova filosofia de prestação de contas, das quais faça parte o relatório de auditoria.

É certo que esse tipo de cultura de prestação de contas não faz parte dos países da Europa continental, mas faz parte das regras dos países anglosaxónicos. Mesmo tendo sido auditadas, as demonstrações financeiras precisam de ser divulgadas, o que, a não ser feito, diminui a sua utilidade.

\subsection{Normas para a Elaboração do Relatório de Auditoria}

Decorrido o trabalho de auditoria, deve elaborar-se um relatório, conforme se prevê nas diferentes normas de auditoria. Por exemplo, as normas INTOSAI referem:

No final de cada fiscalização, o auditor deve preparar por escrito a sua opinião ou informação, evidenciando de forma adequada os factos descobertos; o seu conteúdo deve ser fácil de entender, estar isento de expressões vagas ou ambiguidades, incluir apenas a informação devidamente documentada e, além disso, deve ser independente, objectivo, imparcial e construtivo.

Segundo os Órgãos de Controlo Externo do Estado Espanhol, podem ser estabelecidas normas sobre relatórios de auditoria, que a figura seguinte reproduz: 


\begin{tabular}{|c|c|c|}
\hline & \multirow{6}{*}{ Apresentação em forma adequada } & Forma escrita \\
\hline & & Clareza e uniformidade na linguagem \\
\hline & & Concisão \\
\hline & & Objectividade \\
\hline & & Ponderação \\
\hline & & Adequado fundamento ou suporte \\
\hline & Entrega aos destinatários & Oportunidade \\
\hline & & Destinatários \\
\hline & Adequada preparação & Conformidade com as normas de auditoria \\
\hline & & Adaptação à realidade do sector público \\
\hline & & Alegações do ente auditado \\
\hline & & Identificação dos destinatários \\
\hline & & Razões, objectivos e alcance da auditoria \\
\hline & & Normas de auditoria aplicadas \\
\hline & & Comentário sobre questões e incidências relevantes \\
\hline & & Opinião ou conclusão \\
\hline Normas sobre relatórios & & Recomendações \\
\hline & Conteúdo mínimo do relatório & Data do relatório \\
\hline & & Assinatura \\
\hline & Publicidade & \\
\hline
\end{tabular}

Fonte: AECA (2001, p. 550)

Quadro 5 - Esquema sobre normas relativas ao relatório de auditoria

Relativamente aos diferentes tipos de auditoria, podem incluir-se nos relatórios de auditoria de uma entidade pública os seguintes requisitos (PINA E TORRES: 2001):

\subsection{Auditoria de regularidade (contabilística e de legalidade)}

\section{Estrutura do relatório de regularidade}
1. Objectivo
2. Alcance e limitações
3. Opinião
4. Demonstrações financeiras auditadas
5. Conclusões e recomendações
6. Anexos

\section{Quadro 6 - Adaptado de Pina, V. y Torres, L. (2001)}

\subsection{Auditoria de Economia, Eficiência e Eficácia}

Apesar das limitações existentes numa auditoria dessa natureza, os relatórios de uma auditoria operativa incluem informação relevante sobre a economia, a eficiência e a eficácia na gestão dos recursos públicos.

\section{Estrutura do relatório de programas}

1. Descrição do programa

2. Objectivo, alcance e limitações

3. Conclusões e recomendações gerais

4. Análise de detalhe ou avaliação do Programa

5. Anexos

\section{Quadro 7 - Fonte Adaptado de Pina, V. y} Torres, L. (2001)

Os tipos de opinião utilizados nas entidades públicas, coincidem com a denominação e com a definição dos utilizados no sector privado, ou seja:

- opinião sem reservas;

- opinião com reservas;

- opinião adversa e

- abstenção ou recusa de opinião.

\subsection{Necessidade de um relatório de auditoria externa do sector público simples e independente}

Sobre as características e os conteúdos dos relatórios de auditoria do sector público, constatase a existência de relatórios extensos e pouco perceptíveis nalguns países e de relatórios sintéticos noutros. Observe-se, no entanto, que a qualidade 
da informação deve pesar sobre a quantidade da mesma.

Admitindo que os relatórios de auditoria do sector público seriam rigorosamente iguais aos do sector privado, haveria vantagens para os utilizadores, tanto mais que a familiarização com o modelo constituiria, à partida, um elemento a seu favor.

Mas as particularidades de que se reveste a actividade financeira pública e o distanciamento dos cidadãos da administração pública, quando comparados com o accionista de uma empresa, leva a que se exija mais do relatório do auditor. Estão em causa questões como a avaliação da gestão, a fiabilidade da informação financeira pública, e se nas empresas privadas o principal objectivo é o lucro, nas entidades públicas pretende-se o fornecimento de um leque mais vasto de informação.

Nos Estados Unidos, o auditor emite um relatório curto, que se anexa às demonstrações financeiras auditadas, de aproximadamente 15 páginas. Esse relatório sintético de auditoria que se anexa às demonstrações financeiras, não dispensa a emissão, de forma autónoma, de um relatório analítico tanto da auditoria financeira, como da auditoria da legalidade e performance, bem como de outros aspectos que o auditor considere oportunos. As razões para a defesa de um relatório simples junto às demonstrações financeiras, prendem-se com o facto de se entender que auxilia o utilizador a formular um juízo sobre a fiabilidade das demonstrações financeiras auditadas. Mais tarde, pode vir a ter necessidade de aprofundar alguns aspectos, socorrendo-se então do relatório complementar.

\subsection{Conteúdo do relatório de auditoria}

A falta de normalização nos relatórios de auditoria tem conduzido a que relatórios de auditoria da mesma natureza, produzidos por entidades de controlo distintas ou por diferentes empresas de auditoria, apresentem estruturas díspares, chegando por vezes a que também diferente seja o seu conteúdo.

Ora bem, há elementos indispensáveis a incluir no relatório de auditoria, mas cabe ao órgão de controlo externo ampliar, se assim o entender, o leque de informação a inserir no mesmo, com o objectivo de aumentar a sua compreensão.
Deste modo, os elementos base do relatório de auditoria são os seguintes (MARTÍNEZ Y FLEIXAS: 2002):

- título;

- destinatários;

- as contas e a informação auditada;

- o objectivo;

- as responsabilidades na elaboração da informação e na auditoria;

- descrição do alcance e processo da auditoria, assim como as normas de auditoria aplicadas;

- referência às normas contabilísticas e legais que afectam a informação apresentada;

- comentários e recomendações mais relevantes;

- controlo interno;

- opinião e

- data e dados do auditor.

Convém referir se a auditoria abarcou a totalidade das demonstrações financeiras ou apenas parte delas. Por outro lado, o auditor deve emitir opinião sobre a fiabilidade da informação, a legalidade das operações realizadas e caso se trate de uma auditoria operativa, indicar os seus resultados.

Ao nível dos comentários, sugestões e recomendações, aqueles aspectos que se entenda de mencionar, por exemplo, sobre o controlo interno da entidade, esses devem sê-lo de forma breve, remetendo o detalhe para o relatório complementar.

\section{CONCLUSÕES}

A concepção tradicional de controlo (assente na legalidade), desde há muito que entrou em crise. Por isso, Administração Pública e Gestores Públicos têm procurado novas formas de gestão, que possibilitem a prestação de melhores serviços aos cidadãos. Parece ser também um dado adquirido que os antigos procedimentos de fiscalização não são de modo algum suficientes, e que uma nova cultura de controlo é por demais necessária.

Em Portugal, houve significativas mudanças nessa área, o que pode constatar-se pelas sucessivas reformas do Tribunal de Contas, que Ihe facultaram a adequação aos objectivos de uma instituição moderna de controlo externo.

Em finanças públicas, o controlo assume um papel relevante, à medida que garante a utilização eficaz dos fundos públicos, permite uma gestão 
rigorosa e origina medidas correctivas na acção dos poderes públicos e dos cidadãos, fruto dos relatórios que produz.

A credibilidade de um Estado Democrático, que ao mesmo tempo seja eficiente e transparente junto dos cidadãos, passa também pela existência de órgãos de controlo independentes, dotados de profissionais de elevado perfil técnico e qualificado, dos quais a gestão pública tem muito a beneficiar. Em função desse ponto de vista e na esteira das novas exigências, a prática regular de auditorias no sector público terá de ser instalada.

A função auditoria junto das organizações públicas só é possível se essa cultura se instalar e passar a fazer parte das normas de prestação de contas. Então, tem-se um novo cenário que passa por uma nova filosofia de responsabilidade na gestão (accountability), o que em muito contribuirá para avaliação da eficiência no sector público.

A esse respeito, é bom referir que a auditoria do sector público requer profissionais com um perfil adequado às especificidade e características intrínsecas desse sector, portanto, profissionais de elevada qualidade. E, neste enquadramento, cabe questionar se não estará aqui o alicerce para a criação de uma área de especialização dos Revisores Oficiais de Contas.

\section{BIBLIOGRAFIA}

AECA. Manual de Auditoría del Sector Público. Vol. I e II. Faura Casas: 2001.

BAKER, C. Richard; OWSEN, Dwight M. Increasing the role of auditing in corporate governance. Critical Perspectives on AccountingConference. Baruch College: New York City, 2002.

BOWERMAN, M.; HUMPHREY, C.; OWEN, D. Struggling for supremacy: the case of UK public audit institutions. Critical Perspectives on Accounting, vol. 14, issues 1-2, 2002.

CALLE, M. J. de la Fuente. La fiscalización del Sector Público Autonómico. Especial Análisis de la Cámara de Cuentas de la Comunidad de Madrid. Revista Jurídica de la Comunidad de Madrid, $\mathrm{n}^{\circ}$ 8, Mayo/Septiembr, 2000.

CARRERAS, Juan A.; ROJAS, Antonio Jose. El papel de la auditoria forense en el saneamiento de las funciones gubernamentales. $X$ congreso venezolano de contaduria pública. Nuevas tendencias mundiales que modernizan la profesión, 2002.

COMISIÓN DE COORDINACIÓN DE LOS ÓRGANOS PÚBLICOS DE CONTROL EXTERNO DEL ESTADO ESPAÑOL. Principos y Normas de Auditoría del Sector Público.

COSTA MARQUES, M.C. O controlo económico-financeiro no Sector Público - especial referência às universidades. Revista FISCO, ns 90/91, ano XI, Setembro, 2000,

A Prestação de Contas no Sector Público. Dislivro, 2002.

DESPOUY, Leandro. Una economía sana no puede funcionar sin buenos controles. Presidente de la Auditoría General de la Nación. Disponível em: <www.agn.gov.ar/opinion3.htm>.

HERNANDEZ, Jaime A. ¿Auditoria: Profesion o Negocio? VIII Jornadas de actualización professional. Colômbia. Disponível em:<www.contadoresaic.org $>$.
JEFF EVERETT. The politics of comprehensive auditing in fields of high outcome and cause uncertainty . Critical Perspectives on Accounting, vol. 14, issues 1-2, 2002.

LEI N ${ }^{\circ}$ 91/2001, de 20 de Agosto - Lei do Enquadramento Orçamental.

MALAXECHEVARRIA, Angel G. Fortalecimiento de los Requisitos de Auditoría para Asegurar una Mayor Respoinsabilidad en el Financiameiento Internacional en una Época de Crisis. XVI Annual Conference on New Developments in Governmental Financial Management. Miami, USA, 2002.

MARQUES DE ALMEIDA, J.J. Auditoria: Uma Abordagem Actual. Jornal do Técnico de Contas e da Empresa, n 392 Maio, 1998.

Auditoria: Uma Abordagem Actual. Jornal do Técnico de Contas e da Empresa, n 393 Junho, 1998.

Auditoria: Uma Abordagem Actual. Jornal do Técnico de Contas e da Empresa, n 394 Julho, 1998.

Auditoria: Uma Abordagem Actual. Jornal do Técnico de Contas e da Empresa, $n^{\circ}$ 395/6 Agosto/Setembro, 1998.

; MATOS CARVALHO, J.M. O controlo interno numa grande empresa - verificação das condições básicas. Revista de Contabilidade e Comércio, n ${ }^{\circ}$ 210, Vol. LIII, $2^{\circ}$ trimestre de 1996.

PINA, V.; TORRES, L. Disponível em: <www. ciberconta.unizar.es>, 2001.

POLLITT, Christopher. Performance audit in Western Europe: trends and choices. Critical Perspectives on Accounting, volume 14 , issues $1-2,2002$.

PRINCIPIOS Y NORMAS DE AUDITORÍA DEL SECTOR PÚBLICO. Comisión de Coordinación de los òrganos Públicos de Control Externo del Estado Español. 
PUCHETA MARTÍNEZ, M. Consuelo; CORTÈS FLEIXAS, J. L. Qué son y cómo deberían ser los Informes de Auditoría de las Administraciones Publicas. Revista AECA, $n^{\circ} 58$ / Abril, 2002.

TORRES, Lourdes. La Auditoría operativa un instrumento para la mejora de la nueva gestión pública. Revista $A E C A, \mathrm{n}^{\circ} 61$, Set./Dez., 2002.

TRIBUNAL DE CONTAS. Manual de Auditoria e de Procedimentos, vol. I e II. Ed., Tribunal de Contas, 1999.

VALIÑO CASTRO, Aurelia. Las Reformas de la Administración Pública. Documentos de Trabajo de la Facultad de Ciencias Económicas y Empresariales. Biblioteca de La Facultad de Ciencias Económicas y Empresariales. Universidad Complutense de Madrid, 2002.

VAUGHAN S. RADCLIFFE. What Government Auditors Cannot Know: A Study of Public Secrecy in the Audit of the Cleveland
City Schools. Critical Perspectives on Accounting Conference. Baruch College: New York City, 2002.

WATANABE, Kazuo. Characteristics of Accounting Standards for Independent Administrative Institutions. Government Auditing Review, vol. 9, March, 2003.

Conclusiones dos VII Encuentros Técnicos de los Órganos de Control Externo Espanhol. Noviembre, 2001. Disponível em: $<w w w$. sindicatura.org/cast/novetats $>$.

El Papel Constructivo Del Control Externo II Encuentro sobre Gestión y Políticas Públicas, Ávila, Mayo, 2000. Disponível em: $<w w w . s i n d i c l m . e s / q u e e s / o r g a n i z a c i o n /$ ponencias.htm>.

Evolucion Del Gasto En Las Comunidades Locales. Disponível em: <www.sindiclm.es/ quees/organizacion/pon_ov01.htm>.

YOSHIMI, Hiroshi. Governmental Audit and Administrative Evaluation: From Auditing Perspective. Government Auditing Review, vol. 9, March, 2003.

NOTA:

Endereço dos autores:

Instituto Superior de Contabilidade e Administração de Coimbra

Quinta Agrícola - Bencanta

Coimbra - Portugal

3000 